\title{
A Catalytic Highly Enantioselective Synthesis of Spirooxazolines
}

\author{
Ayham H. Abazid and Boris J. Nachtsheim* \\ University of Bremen, Institute of Organic and Analytical Chemistry, Leobener Straße 7, 28359 Bremen, Germany \\ nachtsheim@uni-bremen.de
}

Supporting Information Placeholder

\begin{abstract}
A catalytic highly enantioselective synthesis of spirooxazolines is presented. Starting from readily available 2-naphthol-substituted benzamides and using catalytic amounts of a chiral triazole-substituted iodoarene catalyst, a variety of spirooxazolines can be isolated through an enantioselective oxidative dearomatization in up to $92 \%$ yield and $97 \%$ ee. The further synthetic utility of the optically enriched spirooxazolines was examined providing a corresponding 2-naphthalenole and an oxepin.
\end{abstract}

Spirocycles are well represented in many natural products and commercial drugs. ${ }^{1}$ These unique molecular scaffolds have the advantage of providing stiff three-dimensional arrangements based on the tetrahedral nature of the spirocarbon. This allows enzyme pocket binding in a highly specific manner in terms of H-bonding, hydrophobic, ${ }^{2}$ and $\pi$-stacking interactions. ${ }^{3}$ While spirocycles can be found in abundance in natural products, they are only rarely found in pure synthetic pharmacophores due to their difficult enantioselective synthesis. A particular underrepresented class of synthetic spirocycles are spiro(is)oxazolines, although they can be found in a variety of natural products such as Agelorin A and B (1a and 1b), isolated from marine sponges of the genus Agelas, ${ }^{4}$ or Calafianin $\mathbf{2}$ from the sponge Aplysina gerardogreeni. ${ }^{5}$ The oxazoline derivatives 3 were extracted from the plant Gemmingia chinensis (Figure 1). ${ }^{6}$

The benefits of spirooxazolines as a unique class of spirocyclic compounds and their potential as highly variable scaffolds in medicinal chemistry and material science are encouraging chemists to develop new strategies for their synthesis. Synthetic strategies of spirocycles in general have been reported based on radical cyclizations, ${ }^{7}$ rearrangements, ${ }^{8}$ oxidative or reductive coupling reactions ${ }^{9}$ and cycloadditions. ${ }^{10}$

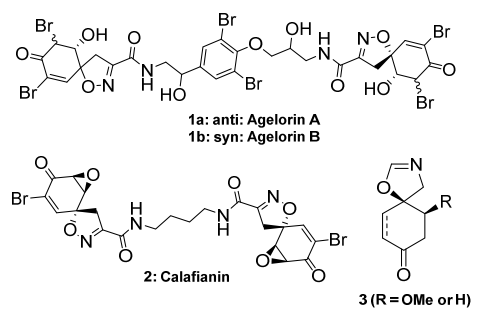

Figure 1. Examples of natural products containing spirooxazoline.

Metal-catalyzed reactions such as the metathesis reaction, the Heck- and the Pauson-Khand reaction ${ }^{11}$ as well as the Nazarov-cyclization ${ }^{12}$ have been applied for the de novo

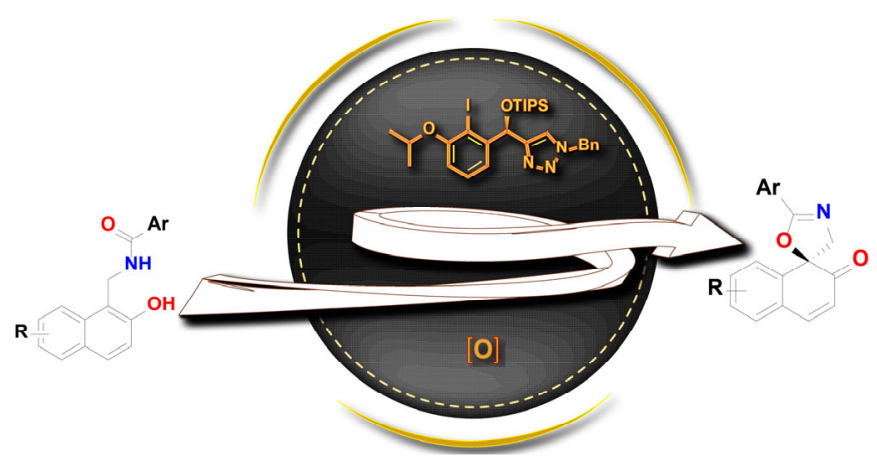

synthesis of spirocyclic scaffolds. A variety of spirocyclic natural-products have been synthesized by metal-catalyzed approaches, such as (-)-vitrenal, ${ }^{13}(+)$-majusculone, ${ }^{14}$ and $\alpha$-acoradiene. ${ }^{15}$ Another important approach for the synthesis of spirocycles is the intramolecular oxidative dearomatization of phenol and naphthol derivatives which can be efficiently accomplished through the application of hypervalent iodine reagents. ${ }^{16,17}$ The first report for such a reaction was in 1998, when Ciufolini et al. reported the oxidative cyclization of tyrosine to form spirolactams, mediated by (diacetoxyiodo)benzene (PIDA) in moderate yields. ${ }^{18}$ Many variants followed. ${ }^{19}$

Enantioselective spirocyclizations, with the Kita-spirocyclization being the most prominent example, have been developed with great success as well. ${ }^{20,21}$ In this regard, spirooxazolines have been widely neglected as target structures for oxidative cyclizations. ${ }^{22}$ Recently, Moran and coworkers determined a new method for synthesizing spirooxazolines through the oxidative cyclization of phenols containing pendent amides mediated by iodine(III). In this seminal report, they also applied this reaction to 2-naphthol using chiral urea-derived iodoarenes, unfortunately with only modest results. In particular the stereoinduction was moderate with $14 \%$ ee in the best case..$^{23}$

Our group recently developed chiral triazole-substituted iodoarenes, and successfully applied these chiral C1-symmetric iodoarene catalysts in a plethora of oxidative enantioselective transformations such as $\alpha$-oxytosylations, (spiro)lactonizations, rearrangements and benzylic hydroxylations..$^{21,24}$ Intrigued by their high reactivity, we wondered whether these omnipotent catalysts can be applied in the yet underexplored generation of spirooxazolines through an oxidiative spirocyclization of suitable substrates. We started our investigations using $N$ - ( (2-hydroxynaphthalen1-yl)methyl)benzamide $\mathbf{4 a}$ as the model compound (Table 1). Oxidative spirocyclization of $\mathbf{4 a}$ by a dearomatizing oxidative $\mathrm{C}$-O-bond connection between the amides carbonyl oxygen and C1 of the 2-napththol unit as shown in Int1 should give spirocyclic 2-naphthalenone $\mathbf{5 a}$. 
We initially investigated four successful catalysts (6a-d) from our recent work (entries 1-4). ${ }^{25}$ It was found that catalyst $\mathbf{6} \mathbf{d}$ showed the highest reactivity and selectivity for the desired product 5a (entry 4). While ethyl acetate and pure HFIP as well as $\mathrm{MeOH} / \mathrm{MeCN}$ mixtures did not improve yields and selectivities (entries 5-7), a further optimization of the reaction conditions revealed a mixture of acetonitrile and HFIP to be a highly effective solvent system (entry 8). Performing the reaction at $0{ }^{\circ} \mathrm{C}$ finally improved the stereoselectivity of product 5a slightly to $96 \%$ ee (entry 9). The absolute configuration of $\mathbf{5 a}$ was proven by comparison between a calculated CD-spectrum and the observed spectrum (see ESI , Figure S-1).

Table 1. Optimization of the reaction conditions.

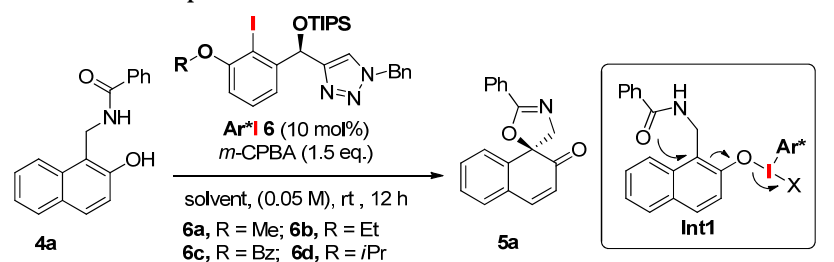

\begin{tabular}{ccccc}
\hline $\begin{array}{c}\text { En- } \\
\text { try }^{[a]}\end{array}$ & $\begin{array}{c}\text { Cata- } \\
\text { lyst }\end{array}$ & Solvent & $\begin{array}{c}\text { Yield } \\
{[\%]}\end{array}$ & $\begin{array}{c}\text { ee } \\
{[\%]}\end{array}$ \\
\hline 1 & $\mathbf{6 a}$ & MeCN & 60 & 67 \\
2 & 6b & MeCN & 68 & 74 \\
3 & 6c & MeCN & 63 & 78 \\
4 & 6d & MeCN & 76 & 85 \\
5 & 6d & EtOAc & 71 & 64 \\
6 & 6d & HFIP & 72 & 76 \\
$7^{[b]}$ & 6d & MeCN:MeOH & 68 & 72 \\
$8^{[b]}$ & 6d & MeCN:HFIP & 80 & 90 \\
$9^{[b, c]}$ & 6d & MeCN:HFIP & 81 & 96 \\
\hline
\end{tabular}

[a] Reaction conditions: 4a $(0.15 \mathrm{mmol}, 1.00$ eq. $)$, cat $(0.015 \mathrm{mmol}, 10 \mathrm{~mol} \%), m$-CPBA ( $0.23 \mathrm{mmol}, 1.50$ eq.), solvent $(0.05 \mathrm{M})$. [b] Ratio of 3:1. [c] Reaction performed at $0{ }^{\circ} \mathrm{C}$ for $16 \mathrm{~h}$ for full conversion of $\mathbf{4 a}$.

Under these optimized conditions, the applicable substrate scope was examined (Scheme 2). Initially, we introduced diverse substituents on the 2-naphthol ring. Halogensubstituents are well tolerated for example giving the 6bromo derivative $\mathbf{5 b}$ in $92 \%$ yield and $93 \%$ ee. 3-Carboxyalkylesters gave spirooxazolines $\mathbf{5 c}$ and $\mathbf{5 d}$ in up to $86 \%$ yield and $88 \%$ ee. 7-Methoxy- and hydroxyderivatives as electron rich examples can also be submitted to the spirocyclization giving $\mathbf{5 e}$ and $\mathbf{5 f}$ with good results. Even though the latter was isolated in high enantioselectivity ( $93 \%$ ee), yield significantly dropped to $54 \%$, possibly due to undesired oxidations of the phenol. A hexahydro 2-napthalenone can be transformed into target compound $5 \mathrm{~g}$ in $84 \%$ and $95 \%$ ee. Next, we varied the substitution pattern of the aryl amide. Introduction of halogen substituents yielded target compounds $\mathbf{5 h}-\mathbf{m}$ with good yields of $64-87 \%$, and enantioselectivities of up to $97 \%$ for the 4-chloro derivative $\mathbf{5 i}$. The presence of strongly electron-withdrawing trifluoromethyl or nitro groups was tolerated as well in the cyclization, resulting in formation of $\mathbf{5 n}$ and $\mathbf{5 o}$ in good yields and excellent enantioselectivities of up to $94 \%$ ee. Methoxy- and ethoxy-substituted arenes $\mathbf{4 p}$ and $\mathbf{4 q}$ gave spirooxazolines $\mathbf{5 p}$ and $\mathbf{5 q}$ in high yields of $91 \%$ and $86 \%$, respectively, with an excellent enantioselectivity for $\mathbf{5 p}$ of $95 \%$ ee and a moderate enantioselectivity of $73 \%$ ee for $\mathbf{5 q}$. A highly electron rich trimethoxy-substituted derivative yielded the corresponding spirooxazoline $\mathbf{5 r}$ in high yield, but with a diminished enantioselectivity of $70 \%$ ee. A 2'pyridine-substituted amide was also tolerated in this cyclization, forming the corresponding spirooxazoline $\mathbf{5 s}$ with $82 \%$ yield and $81 \%$ ee.

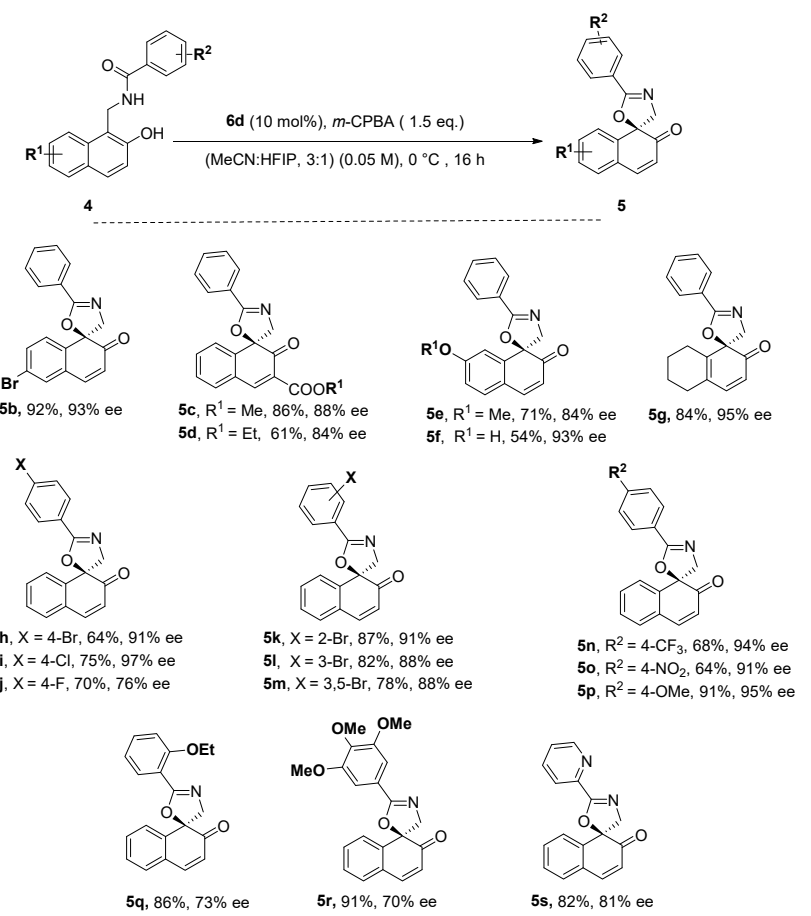

Scheme 2. Substrate scope.

To prove the synthetic robustness of our method, a largescale synthesis was performed, giving spirooxazoline $\mathbf{5 a}$ in constant yield and enantioselectivity on a $4 \mathrm{mmol}$ scale. (Scheme 3 - a).

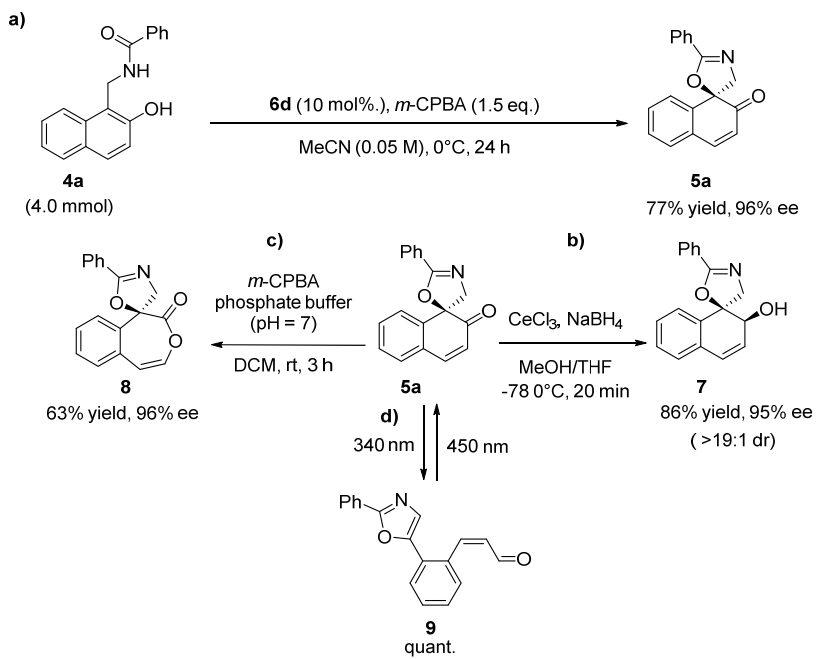

Scheme 3. Synthetic applicability. 
The further synthetic utility of the optically enriched spirooxazolines was also investigated. A diastereoselective Luche reduction of $\mathbf{5 a}$ yielded the C2-spirocyclic tetrahydronaphthalenole 7, with almost the same enantiopurity (Scheme 3 - b). ${ }^{26}$ By addition of $m$-CPBA 5a was oxidized through a Baeyer-Villiger oxidation to the oxepin $\mathbf{8}$, again with excellent retention of the stereocenter (Scheme 3-c). Interestingly, this reaction was not observed during our previous investigations as a potential side reaction.

Spiropyrans and spirooxazines received attention in material science due their reversible photoresponsive properties. ${ }^{27}$ Industrial applications of spirooxazines include photoresponsive sunglasses and ophthalmic lenses. ${ }^{28}$ In this regard, the closed form $\mathbf{5 a}$ could potentially undergo ring opening after photoactivation, either by heterolytic cleavage of the $\mathrm{C}$ (spiro)- $\mathrm{O}$ bond or electrocyclization, to give the open form, which absorbs at a longer wavelength due to an extended $\pi$-system. ${ }^{29}$ We used $340 \mathrm{~nm}$ light for the photoisomerization reaction of spirooxazoline $\mathbf{5 a}$ to construct the open form 9, which has a yellowish color. The aldehyde 9 absorbed light at $450 \mathrm{~nm}$ to revert to the closed form $\mathbf{5 a}$ as the racemate (Scheme $3-\mathrm{d}$ ). This is a rare case of a switchable optical active spirooxazine and further applications in chiral optical devices are under current investigations.

In conclusion, we herein present the first highly enantioselective oxidative spirocyclization of amide-substituted 2-naphthols using chiral hypervalent iodine catalysis. This method provides a variety of enantioenriched spirooxazolines in remarkable yields and enantioselectivities. The reaction is compatible with a wide variety of substrates, including electron-rich and electron-poor naphthalene benzamides as well as $N$-heterocycles. The further synthetic utility of these compounds allows the preparation of two interesting derivatives by a diastereoselective 1,2-reduction of the 2-naphthalenone and ring-enlargement through a Baeyer-Villiger oxidation. Finally, the principle photoswitchable properties of the so observed chiral spirooxazoline is demonstrated.

\section{ASSOCIATED CONTENT}

\section{Supporting Information}

All supporting information is available free of charge on the ACS Publications website at DOI: XXX. This includes all experimental procedures and characterization data.

\section{AUTHOR INFORMATION}

\section{Corresponding Author}

Boris J. Nachtsheim- University of Bremen, Institute of Organic and Analytical Chemistry, Leobener Straße 7, 28359 Bremen, Germany; orcid.org/0000-0002-3759-2770

Email:nachtsheim@uni-bremen.de

\section{Authors}

Ayham H. Abazid- University of Bremen, Institute of Organic and Analytical Chemistry, Leobener Straße 7, 28359 Bremen, Germany; orcid.org/0000-0002-4204-4701

\section{Author Contributions}

The manuscript was written by Ayham H. Abazid and Boris J. Nachtsheim. Ayham H. Abazid performed the experiments. All authors have given approval to the final version of the manuscript.

\section{Notes}

The authors declare no competing financial interests.

\section{ACKNOWLEDGMENT}

Ayham H. Abazid acknowledges the Scholars at Risk organization for personal funding.

\section{REFERENCES}

(1) a) Saraswat, P.; Jeyabalan, G.; Hassan, M. Z.; Rahman, M. U.; Nyola, N. K. Synth. Commun. 2016, 46, 1643-1664; b) Zheng, Y.; Tice, C. M.; Singh, S. B. Bioorg. Med. Chem. Lett. 2014, 24, 36733682; c) Zheng, Y.-J.; Tice, C. M. Expert opinion on drug discovery 2016, 11, 831-834; d) Hong, L.; Wang, R. Adv. Synth. Catal. 2013, 355, 1023-1052; e) Ding, A.; Meazza, M.; Guo, H.; Yang, J. W.; Rios, R. Chem. Soc. Rev. 2018, 47, 5946-5996; f) Singh, G. S.; Desta, Z. Y. Chem. Rev. 2012, 112, 6104-6155;

(2) Carreira, E. M.; Fessard, T. C. Chem. Rev. 2014, 114, 82578322.

(3) a) Aher, R. B.; Roy, K. Comb. Chem. High Throughput Screen. 2015, 18, 217-226; b) Graus, S.; Uriel, S.; Serrano, J. L. Cryst.Eng.Comm. 2012, 14, 3759;

(4) D. Wright, A.; M. König, G. Heterocycles 1993, 36, 1351.

(5) Encarnación, R. D.; Sandoval, E.; Malmstrøm, J.; Christophersen, C. J. Nat. Prod. 2000, 63, 874-875.

(6) Xiao, S.-J.; Guo, D.-L.; Zhang, M.-S.; Chen, F.; Ding, L.-S.; Zhou, Y. J. Asian. Nat. Prod. Res. 2016, 18, 719-723.

(7) Sannigrahi, M. Tetrahedron 1999, 55, 9007-9071.

(8) KRAPCHO, A. P. Synthesis 1976, 1976, 425-444.

(9) KRAPCHO, A. P. Synthesis 1974, 1974, 383-419.

(10) KRAPCHO, A. P. Synthesis 1978, 1978, 77-126.

(11) Rios, R. Chem. Soc. Rev. 2012, 41, 1060-1074.

(12) D'yakonov, V. A.; Trapeznikova, O. A.; Meijere, A. de; Dzhemilev, U. M. Chem. Rev. 2014, 114, 5775-5814.

(13) Kodama, M.; Tambunan, U. S. F.; Tsunoda, T.; Itô, S. BCSJ. 1986, 59, 1897-1900.

(14) Taber, D. F.; Sikkander, M. I.; Storck, P. H. J. Org. Chem. 2007, 72, 4098-4101.

(15) Tashiro, T.; Kurosawa, S.; Mori, K. Biosci. Biotechnol. Biochem. 2004, 68, 663-670.

(16) a) Zhdankin, V. V. Hypervalent iodine chemistry: Preparation, structure, and synthetic applications of polyvalent iodine compounds / Viktor V. Zhdankin, Department of Chemistry and Biochemistry, University of Minnesota Duluth, Minnesota, USA; John Wiley \& Sons Ltd, Chichester, West Sussex, 2014; b) Wirth, T.; Antonchick, A. P. Hypervalent iodine chemistry; Springer Verlag, Switzerland, 2016;

(17) a) Singh, F. V.; Kole, P. B.; Mangaonkar, S. R.; Shetgaonkar, S. E. Beilstein. J. Org. Chem. 2018, 14, 1778-1805; b) Hempel, C.; Weckenmann, N. M.; Maichle-Moessmer, C.; Nachtsheim, B. J. Org. Biomol. Chem. 2012, 10, 9325-9329; c) Dohi, T.; Kita, Y. Chem. Commun. 2009, 2073-2085; d) Zheng, Z.; Zhang-Negrerie, D.; Du, Y.; Zhao, K. Sci. China Chem. 2014, 57, 189-214; e) Claraz, A.; Masson, G. Org. Biomol. Chem. 2018, 16, 5386-5402; f) Flores, A.; Cots, E.; Bergès, J.; Muñiz, K. Adv. Synth. Catal. 2019, 361, 1; 
(18) Braun, N. A.; Ciufolini, M. A.; Peters, K.; Peter, E.-M. Tetrahedron. Letters 1998, 39, 4667-4670.

(19) a) Lee, E.; Hwang, Y.; Kim, Y. B.; Kim, D.; Chang, S. J. Am. Chem. Soc. 2021; b) Alves, N. G.; Alves, A. J. S.; Soares, M. I. L.; v. d. Pinho e Melo, T. M. Adv. Synth. Catal. 2021, 363, 2464-2501;

(20) a) Uyanik, M.; Yasui, T.; Ishihara, K. Angew. Chem. Int. Ed. 2010, 49, 2175-2177; b) Uyanik, M.; Sasakura, N.; Mizuno, M.; Ishihara, K. ACS. Catal. 2017, 7, 872-876; c) Uyanik, M.; Yasui, T.; Ishihara, K. J. Org. Chem. 2017, 82, 11946-11953; d) Hempel, C.; Maichle-Mössmer, C.; Pericàs, M. A.; Nachtsheim, B. J. Adv. Synth. Catal. 2017, 359, 2931-2941;

(21) Abazid, A. H.; Nachtsheim, B. J. Angew. Chem. Int. Ed. 2020, $59,1479-1484$.

(22) a) Zhou, H.; Topiol, S. W.; Grenon, M.; Jimenez, H. N.; Uberti, M. A.; Smith, D. G.; Brodbeck, R. M.; Chandrasena, G.; Pedersen, H.; Madsen, J. C.; Doller, D.; Li, G. Bioorg. Med. Chem. Lett. 2013, 23, 1398-1406; b) Qu, C.; Wu, Z.; Li, W.; Du, H.; Zhu, C. Adv. Synth. Catal. 2017, 359, 1672-1677;

(23) a) Tariq, M. U.; Moran, W. J. Eur. J. Org. Chem. 2020, 2020, 5153-5160; b) Tariq, M.; Moran, W. J. Tetrahedron 2020, 76, 131634;

(24) Abazid, A. H.; Clamor, N.; Nachtsheim, B. J. ACS. Catal. 2020, $10,8042-8048$.
(25) Abazid, A.; Hollwedel, T.-N.; Nachtsheim, B. Stereoselective Oxidative Cyclization of N-Allyl Benzamides to Oxazolines, 2021.

(26) Luche Reduction. In Comprehensive Organic Name Reactions and Reagents; Wang, Z., Ed.; John Wiley \& Sons, Inc: Hoboken, NJ, USA, 2010.

(27) a) Minkin, V. I. Chem. Rev. 2004, 104, 2751-2776; b) Lokshin, V.; Samat, A.; Metelitsa, A. V. Russ. Chem. Rev. 2002, 71, 893-916; c) Li, C.; Zhang, Y.; Hu, J.; Cheng, J.; Liu, S. Angew. Chemie. 2010, 122, 5246-5250; d) Chen, Q.; Feng, Y.; Zhang, D.; Zhang, G.; Fan, Q.; Sun, S.; Zhu, D. Adv. Funct. Mater. 2010, 20, 36-42; e) Grzelczak, M.; Vermant, J.; Furst, E. M.; Liz-Marzán, L. M. ACS. Nano. 2010, 4, 3591-3605; f) Zhu, M.-Q.; Zhang, G.-F.; Li, C.; Aldred, M. P.; Chang, E.; Drezek, R. A.; Li, A. D. Q. J. Am. Chem. Soc. 2011, 133, 365372 ;

(28) Nigel Corns, S.; Partington, S. M.; Towns, A. D. Coloration Technology 2009, 125, 249-261.

(29) Klajn, R. Chem. Soc. Rev. 2014, 43, 148-184. 